\title{
A Publicidade Eleitoral na Construçao do Referencial Simbólico Político Partidário do Eleitor Brasileiro
}

\author{
Neusa Demartini Gomes \\ Universidad Católica de Río Grande do Sul, Brasil
}

\begin{abstract}
Resumo: El articulo forma parte de la divulgación de las conclusiones de un amplio proyecto de investigación que tiene como objetivo, verificar como está siendo construido el referencial simbólico político-partidario del elector brasileño. Por tanto, fueron realizadas tres etapas de investigación: a) entrevistas con los candidatos y las directivas de los partidos políticos, para conocer sus intenciones de comunicación y su nivel de conocimiento sobre los símbolos oficiales de sus partidos; b) análisis de los mensajes de propaganda electoral vinculadas durante el periodo oficial de las campañas, con la intención de encontrar tipologías específicas, y c) entrevistas con el elector, para verificar su nivel de conocimiento de los simbolos políticos-partidarios.

Abstract: This text brings to light the findings of a wide research project that objective was to discovery how the symbolic political and party referential are been constructed in the minds of Brazilian voters. For such, we have been working according to three main lines of research: a) interviews with the candidates and the staff of the political parties, in order to get how their communications strategy and their degree of knowledge about the official symbols of their parties; b) message analysis of electoral propaganda disseminated by the parties during the legal period before elections, to find out specific sign types used during their campaigns; c) interviews with voters, to verify their degree of familiarity symbols of their parties.
\end{abstract}

\section{Introdução}

$\mathbf{E}$

ste texto faz parte da divulgação das conclusões de um amplo projeto de pesquisa que teve como objeto a comunicação eleitoral brasileira, em suas três vertentes principais: emissor (partido e candidato), mensagem (campanhas publicitárias eleitorais) e receptor (eleitor). Para tanto, foram realizadas também três etapas: a) pesquisa com os candidatos e os partidos políticos, para conhecer suas intenções e seu nível de conhecimento sobre os símbolos oficiais de seus partidos; b) análise de conteúdo das mensagens de publicidade e/ou propaganda, veiculadas durante o período oficial das campanhas, com a intenção de encontrar tipologias específicas, e c) pesquisa sobre a construção do referencial simbólico político-partidário dos eleitores. 
O objetivo principal foi o de, conhecendo as intenções de comunicação, as mensagens transmitidas pelos mass-media e o referencial simbólico formado, fornecer elementos, a partir de uma análise combinada, que sirvam de paradigma para uma forma de comunicação política preocupada com o desenvolvimento da cultura cívica ou de participação cidadã.

O Brasil é, dentre os países democráticos, talvez o que dedica maior período para a publicidade das campanhas eleitorais. Já em alguns outros países latinoamericanos e, em geral, nos países europeus, normalmente as campanhas eleitorais, tanto para os cargos majoritários quanto para as representações políticas locais, duram, como máximo, de três a quatro semanas.

Nosso tempo oficial é de sessenta dias, porém este período regulamentado pela legislação eleitoral, refere-se somente à publicidade gratuita em rádio e televisão, no que nosso modelo é um meio caminho entre o americano e o francês. Quanto à veiculaçao de spots pagos pelos partidos, nao há impedimento legal que proiba fazê-lo durante todo o ano e, para as peças gráficas tampouco existe uma legislação específica, a nao ser no que se refere ao tamanho do suporte, isto quando anunciado em jornal. A legislaçao, portanto, permite, que os candidatos (ou candidatos a candidatos) as façam chegar ao público em geral, às vezes, até seis meses antes das eleições e já se tem registros de casos em que isto aconteceu com até um ano de antecedência das eleições.O ano de 1998 será de eleiçoes (em outubro) para cargos estaduais e nacionais -incluindo presidência da repúblicae já estão, no ar, e intensamente, anúncios em forma de spots, com duração de trinta segundos (alguns com mais), desde janeiro.

Logo, o horário político à disposição dos partidos no rádio e na televisão em cadeia nacional, é usado durante todo o ano, por todos os partidos que tem direito a ele, além de spots pagos, atualmente muito utilizados também pelos partidos melhores estruturados, como é o caso do PMDB,PTB, PT, PDT, PPS, PPB, PFL e PSDB, em midia nacional. Essa última forma é a novidade do último ano para os brasileiros, e vem com um tratamento técnico também como forma de comunicação política persuasiva, quando, pela necessidade de referenciais constatada pelas pesquisas, deveria ser informativa, o que a faz não se enquadrar na propaganda política, mas sim, na publicidade dita eleitoral. Todos os spots que foram veiculados em 1997 visavam mais à 
afirmação individual de nomes à futuras candidaturas, do que à fixação dos referenciais símbolicos partidários, que incluem desde os aspectos gráficos, normalmente os referenciais ideológicos e os programas dos partidos emissores.

\section{Um estudo interdisciplinar entre a sociologia e a comunicação políticas}

Se levarmos em consideração os dois aspectos sob os quais as campanhas eleitorais podem ser avaliadas- tanto os quantitativos, quanto os qualitativos- veremos que elas fazem parte também, de uma forma de pensamento (muito brasileiro) caracterizada pelo desperdício e que vem sendo estudada por sociólogos, uma vez que a nossa sociedade, em geral, apesar de já ter-se dado conta, não vem reagindo racionalmente contra essa postura. Quantitativamente, nossas eleiçoes configuram uma prática bastante saturativa, enquanto que, qualitativamente cai no mesmo adjetivo. Os resultados dêsse desperdício apareceram recentemente: apesar de toda essa carga ter sido repassada pela comunicaçao política, através da propaganda, da publicidade eleitoral ou pelo espaço que as notícias políticas ocupam nos jornais, rádios e televisões nacionais, as últimas pesquisas do Instituto Brasileiro de Geografia e Estatística (IBGE), que ouviu 22,5 milhoes de pessoas nas seis principais regiões metropolitanas (São Paulo, Rio de Janeiro, Porto Alegre, Salvador, Recife e e Belo Horizonte) concluiu que, dois em cada dez brasileiros desconhece o nome do Presidente da República e também do Prefeito de sua cidade, símbolos majoritários da cultura cívica democrática ocidental. Para os Governadores, a relação é ainda mais desfavorável: três em cada dez pessoas ouvidas não sabiam quem governa o seu Estado. Esse resultado corresponde às regioes mais desenvolvidas do país, o que indica que alí, também, o nível de participação política direta é extremamente baixo.

Constatou-se pois, que a publicidade eleitoral infelizmente no Brasil, pelo tempo que dura e pela maneira como é tratada, além de representar, por si mesma, um dos melhores elementos para a indução ao voto, vem sendo também um dos piores para o desenvolvimento da cultura cívica, pelo menos para os segmentos sociais menos favorecidos econômicamente, os quais representam a maior porcentagem de eleitores. Uma pesquisa, aplicada em 1994 a um grupo heterogêneo de eleitores, demonstrou que a maior parte deles era 
informado sobre assuntos políticos por meio da publicidade eleitoral, ou seja, antes das eleições e, restrito ao tema das candidaturas. Outro importante grupo admitiu que fica sem informar-se sobre assuntos políticos quando nao se está em épocas de eleições.

Isto não significa que a publicidade eleitoral não faça parte do sistema global de comunicação de um país democrático mas, quando ela se torna a mais importante via de comunicação dos partidos e candidatos com o eleitorado e, assim mesmo, em forma de monólogo, há que preocupar-se, já que a função explícita desta forma de comunicação persuasiva não é a de, principalmente, informar, além do que, não podemos esquecer que, em qualquer de suas formas, seja comercial ou eleitoral, a publicidade sempre será uma via de apenas uma mão. Uma dupla via de comunicaçao entre cidadãos e autoridades do sistema, e vice-versa, deveria ser, em todas as campanhas, uma constante no diálogo entre candidatos e eleitores.

Com essa preocupação, é importante que se realizem sistematicamente pesquisas na área da comunicação política, em sua vertente eleitoral, para medir a sua ação na construção dessa cultura cívica, de cidadania e de participação, já que, devemos enfatizar a importância dela (a cultura) para os processos de consolidação democrática, afirmação esta que, sem dúvida, vem encontrando eco entre vários cientistas políticos, como por exemplo, Reis(1992), Di Palma (1991), Prezeworski (1992) e Touraine (1992).

É fato notório que, no Brasil, a televisão é a grande protagonista nas eleições a qualquer nível (federal, estadual ou municipal), seguindo a tradição do marketing comercial, cujas técnicas foram transladadas às campanhas políticas sem nenhuma adaptação ao tipo de objetivo que se pretende atingir. Esta afirmação está baseada na observação de tipologias detectadas e na análise de conteúdo das peças publicitárias eleitorais, que não fazem diferença entre os objetos comerciais, de um lado e, políticos, de outro. Há diferenças marcantes entre mudar um comportamento em relaçao a uma açao de compra e um comportamento ideológico político. Recentemente, na seção política do maior jornal de Porto Alegre, o sub-título de uma matéria sobre a disputa interna do PMDB (maior partido nacional) refería-se ao fato de que "o partido divulgará uma série de comerciais convocando dirigentes e delegados para a convenção do dia 8 de março" (Zero Hora: 8). Está tão introjetado na mente do eleitor brasileiro esta forma 


\section{A Publicidade Eleitoral na Construçao do Referencial Simbólico Político Partidário do Eleitor Brasileiro}

de fazer campanha, que mesmo um jornalista já nao diferencia mais entre uma técnica de comunicação política com outra de comunicação comercial...

As peças gráficas são também importantes estimuladores do voto e tradicionalmente bastante usadas, pois na nossa cultura, o contato porta a porta (canvassing) influi positivamente para a decisão, independente de afinidade ideológica. Pode ser um paradoxo, mas mesmo entre a populaçao analfabeta e semianalfabeta brasileira (representada por $18 \%$ da populaçao total do país e, mais concentrada nas regiões norte e nordeste), os suportes gráficos conhecidos vulgarmente como "santinhos" (volantes) ganham um valor expressivo, além do semântico, uma vez que representam um bem material que os eleitores recebem em troca do voto, o que por si só oferece um tema para uma investigaçao mais profunda sobre a sua recepção.

Somados os esforços publicitários (em tempo e verba) distribuidos pela televisão, rádio e peças gráficas, também podemos afirmar que o Brasil é um dos países que mais gasta em publicidade eleitoral. A pesquisa para a realização de minha tese doutoral ${ }^{1}$, demonstrou que os "santinhos", distribuidos pelos candidatos a vereadores nas eleições municipais de Porto Alegre ${ }^{2}$ em 1992, somaram um total de 138 milhões de exemplares. Porém o retorno deste investimento é muito pouco, em termos de aproveitamento ideal na comunicação com o público eleitor, se levarmos em consideraçao que a funçao da campanha nao é somente a de levar o indivíduo a uma açao de voto. $\mathrm{O}$ que acontece no Brasil é que os partidos, seguindo a tradição norteamericana sao: pouco ideologizados, nacionais por agregaçao regional e funcionando sazonalmente nos períodos eleitorais. Além do que, nao temos ainda um quadro partidário definido ${ }^{3}$. A cada ano a oferta eleitoral partidária muda, e mudam-se os candidatos de um

1 GOMES, N.D. -"Los volantes como comunicación política en las elecciones municipales brasileñas, en Porto Alegre - RGS - 1988-1992". Universidad Complutense de Madrid Facultad de Ciéncias de la Información, Departamento de Sociologia VI. 467 páginas.

2 Porto Alegre é a capital do Estado do Rio Grande do Sul, com uma populacao total de 1.500.000 habitantes e 800.000 eleitores, com um índice de analfabetismo de 3,4\%.

3 Foram pesquisados 27 partidos registrados no TSE, sendo que 17 forneceram todas as informacoes necessárias para o inventário simbólico visual partidário. 
partido a outro, sem nenhum critério que nao o de conseguir eleger-se, independente de ideologia. Ora, esta forma de atuação procura então, em épocas de eleições, tirar o máximo do tempo disponível de comunicação com o eleitorado para levá-lo sómente a uma ação de voto, e sem a preocupação de, por sua vez, reforçar na mente do eleitor aqueles elementos que identificam os partidos que fazem parte do quadro político brasileiro, quanto mais, ideologizá-lo.

Nao há dúvida de que há uma confusão de referentes símbolicos dos partidos políticos brasileiros generalizada em todas as camadas sociais da população votante e, inclusive, entre os próprios candidatos ao cargo de vereador: Muitos deles, conforme ficou demonstrado em outra pesquisa realizada recentemente, mal conheciam os símbolos e signos de seus partidos políticos e dos demais partidos concorrentes. A nossa publicidade eleitoral passou, usando palavras de Gonzalez Martin (1990: 81), portanto, da simbolização ao estereótipo e do estereótipo ao ruido e à contaminação, quando sabemos que, na comunicação política o símbolo deveria ser uma ordenação e uma organização da realidade, e deveria ser utilizado nas campanhas publicitarias eleitorais para ajudar-nos a entender cada momento em que estamos.

O que se constata, porém, é que atualmente, no Brasil, os símbolos políticos, em sua maior parte, estão desnaturalizando-se e se repetem com sentidos diferentes aos de sua orígem, ${ }^{4}$ e uma mesma representação simbólica serve tanto para uma comunicação de um determinado partido político, quanto de outro, que até mesmo nao tenham afinidade ideológica entre sí. Vemos pois, que os limites se apagam e as mensagens não facilitam, mas sim contaminam a comunicação.

O papel das campanhas eleitorais é o de ir muito além da mera publicidade eleitoral, o que difícilmente ocorre no nosso país, onde sabemos que todo o esquema de campanhas está montado em torno do objetivo "eleitoreiro". E preciso primeiro informar o cidadão que vota,

4 Dentre os suportes gráficos utilizados nas campanhas de 30 candidatos ao cargo de vereador e analisados pela pesquisadora, 28 deles continham elementos visuais alheios ao conjunto de símbolos que fazem parte das referencias partidárias, o que reforca nossa tese sobre a forma "personalista" de fazer política do político brasileiro. 
selecionando os elementos objetivos, que o manterão informados sobre as intençoes e os programas do partido, e depois sim, persuadí-lo, tentando influir no seu comportamento eleitoral, de maneira a convencê-lo ou reforçar a sua idéia de dar o voto ao partido ou candidato emissor. A campanha eleitoral, num total esforço de approach, usando todos os seus recursos de comunicaçao, deve ter o compromisso da ideologizaçao, deixando à publicidade a responsabilidade pela difusão dos símbolos políticos, já que vivemos a época em que uma das características dos processos deveria ser a polarização de atitudes em volta de elementos simbólicos.

A informação dada pelas campanhas não deveria unicamente a ilustrar os dados referentes a uma situaçao eleitoral concreta, como sempre ocorre. Existe já uma acumulação de informações durante a vida do cidadão, recebidas pelas campanhas eleitorais de toda a sua vida, mas no caso brasileiro, a cada ano o eleitor recebe informações até contraditórias e paradoxais, difíceis de administrar. A campanha deveria administrar esta informação acumulada, caso fôsse repassada corretamente, numa ação educacional e portanto, socializadora do conhecimento político. Cabe observar que, num país como o nosso, uma caampanha deveria contribuir mais à educação que simplesmente a uma seleção política.

Esta parte da pesquisa, a partir do inventário e posterior estudo desses símbolos serviu para verificar se o cidadão, eleitor ou não, recebeu nas mensagens, elementos tais como logotipos, cores, grafismos etc., como uma primeira abordagem que contribui para o correto e claro reconhecimento das instituições políticas partidárias, auxiliando-os na formação e na organização do seu imaginário político partidário, ou seja, se o repertório imaginário politico corresponde ao repertório real, independente da intenção de comunicação do candidato com o eleitorado, intenção esta que normalmente se reduz a uma expectativa no retorno através do voto. Esclarecemos que os dados pesquisados sào considerados como os referentes mais primários que deveriam fazer parte da cultura cívica de participação.

O estudo da comunicação política, ou das relações entre o poder político e o seu eleitorado, é uma zona interdisciplinaria entre a sociologia política e o estudo dos meios de comunicação de massas e, sendo esta uma pesquisa típica de análise de campanhas, em sua vertente da publicidade eleitoral, teve algumas hipóteses a respeito de 
sua eficácia, só que neste estudo tomamos o conceito de eficácia, não em função do retorno de votos mas sim, em função de crescimento da cultura cívica do cidadão, uma vez que o reconhecimento dos símbolos das instituições partidárias, as quais já nos referimos, faz parte da cultura política. Buscou pois, verificar qual o referencial simbólico dos eleitores a respeito dos partidos que representavam a oferta eleitoral, no caso específico das eleições municipais.

\section{Esclarecendo os termos usados}

O termo publicidade foi utilizado nesta pesquisa conforme a tradiçao européia, ou seja, uma forma impessoal de comunicação transmitida através de meios pagos por um patrocinador identificado, já que, no Brasil, predomina uma indefiniçao conceitual entre publicidade e propaganda. Assim, no presente estudo, toda vez que nos referirmos ao esforço de comunicação informativa/persuasiva representado na utilização do horário gratuito eleitoral, e de peças gráficas distribuidas durante o período legal de campanha eleitoral, falaremos de publicidade eleitoral, pois consideramos que não houve, no Brasil, até agora, muitas diferenças entre os esforços publicitários que se faz para vender um produto comercial, e aqueles que se faz para vender a imagem de um candidato no período específico das campanhas eleitorais.Os comunicadores responsáveis pelas campanhas eleitorais, principalmente os profissionais de publicidade brasileiros, infelizmente, em sua maior parte, tratam candidatos e partidos como simples produtos a serem colocados no mercado. No Brasil, infelizmente, o mercado eleitoral se dá num nível de competição como no mercado comercial e, nas eleições municipais se pode dizer que se faz um tipo de publicidade que visa somente difundir um candidato entre os eleitores, e em regime de mercado altamente competitivo. Pela atual legislaçao, se pode constatar que o adversário político de um candidato sao, além dos outros, os candidatos de seu próprio partido. Usando a expressao de Herreros Arconada (1989), a diferença entre os dois mercados, nas circunstâncias que estamos analisando reside em, simplesmente, substituir a palavra lucro por voto.

Para propaganda, preferimos recorrer ao sentido que tanto o idioma latino quanto o inglês utilizam, uma vez que tem a mesma raiz etmológica, por isso, transcrevemos as palavras de Gurevich (1981:7) para quem propaganda significa toda ação organizada com o fim de estender, difundir uma opinião, uma religião ou uma doutrina. 
A comunicação política utiliza uma forma específica de linguagem propagandística, e portanto, exige um grau maior de matização, dada a importância que alcançou a criação e a produção das suas mensagens. A sua função predominante é a difusão e implantação de idéias, geralmente abstratas e sem conteúdo referencial específico, a uma ampla massa, quanto maior melhor, de pessoas. Em vista disso, a comunicação política existe porque se concretiza em certas manifestações publicitárias; assim, por exemplo, o atual Movimento dos Sem Terra, seria um debate político árduo e estéril, se não fôsse pelas concretizações visuais gráficas que aparecem junto às manifestações. Estas visualizações trazem de maneira parcial e fragmentada a complexidade real da polêmica, mas ao mesmo tempo, criam as referências para os espectadores.

Trabalhamos o conceito de cultura cívica dado por Almond e Verba (1970: 31), de participação cidadã, e no que se refere somente aos esforços gerais voltados a desenvolver a cidadania e especificamente no que diz respeito aos símbolos e representações da vida política-partidária, tais como a representação popular por meio de cargos públicos, os partidos políticos, e os direitos e os deveres do cidadão.

Os referentes simbólicos objeto da análise sao os que constituem os elementos icônicos dos partidos políticos que concorreram às eleições, utilizados nas mensagens publicitárias, em forma de texto ou de ilustrações; logotipos; cores; fotografias; grafismos; formatos, tópicos de programa; tópicos ideológicos etc.

Por estar destinada a um tipo especial de público -o eleitor-a propaganda eleitoral deveria ter, sem dúvida, algumas características bastante diferenciadas daquelas campanhas publicitárias consideradas como comerciais. Cabe aqui uma observação: a legislação brasileira utiliza a expressão "propaganda eleitoral", também sem conceituá-la, o que nao ocorre em legislações de outros países, e por isso sempre há margem para interpretações casuísticas. $\mathrm{Na}$ campanha publicitária eleitoral os protagonistas do processo de comunicação são:

a) Um emissor, denominado candidato, partido político ou coligação, cujas intenções de comunicação não são menos inferíveis e que se situam na dimensão política-eleitoreira; 
b) Uma mensagem em forma de anúncios eleitorais e que tem como objetivos provocar ou reforçar a adesão do eleitor ao candidato e/ou ao partido político ou coligação, e cujo conteúdo deveria ser o programa de ação de governo municipal, programa esse surgido a partir das necessidades pesquisadas entre os cidadaos;

c) Alguns canais aos quais, dependendo da legislação eleitoral vigente, os emissores tem acesso e que deveriam, por sua vez, possuirem uma mao dupla, para que o eleitor tivesse a chance de manifestar-se;

d) Alguns receptores, cujo conjunto se denomina eleitorado ou corpo eleitoral, ou seja, o segmento da sociedade que a legislação reconhece o direito ou dever do voto e,

e) $\mathrm{O}$ feed-back ou os resultados eleitorais (previstos por meio de pesquisas eleitorais - pré e pós- refletidos pelo número de votos de cada candidato e/ou partido ou coligação no cômputo final das eleições) e, principalmente, as pesquisas posteriores à posse dos candidatos no cargo, para que se saiba se a opinião do público formado pelos seus eleitores é favorável a sua atuação.

Antes de detalharmos a pesquisa, consideramos de interesse examinar, ainda que de forma suscinta, alguns elementos que julgamos importantes no contexto geral da publicidade eleitoral.

A campanha publicitária eleitoral em países de tradição democrática têm objetivos bem claros: planejar, criar, produzir e difundir alguns suportes com mensagens que influenciem as atitudes e as condutas dos eleitores a votarem num determinado partido ou candidato, a um cargo público. Para tanto, estas mensagens divulgarão idéias, programas, atuações de partidos ou de candidatos. Mendelsohn (1973: 129) atribui o êxito de uma campanha eleitoral, não sómente a que estejam integradas às açoes parciais dentro de um plano de marketing, mas também ao fato de que devem estar fundamentadas sobre "a oferta de um programa-promessa de serviços, em redor do qual estruturam-se os argumentos a empregar nos diferentes meios selecionados para difundí-los". Notamos, numa análise de conteúdo das peças brasileiras, um enorme distanciamento dos objetivos que deveriam ser considerados como prioridade na comunicação política, num país que caracteriza-se por uma cultura cívica subdesenvolvida. 
Existem algumas funções manifestas no papel das campanhas eleitorais, bastante importantes como para serem levadas em consideraçao por aqueles que pretendam contribuir para a consolidaçao da democracia, tais como: a) funções de conversão, onde seu objetivo seria converter uma serie de demandas dos sujeitos do sistema numa resposta por parte das autoridades do mesmo, e b) funções de comunicação política que, entre autoridades e sujeitos do sistema político se vê, forçosamente, incrementada durante o período eleitoral. As campanhas fariam possível esta comunicação política, dos eleitores às possiveis autoridades do sistema e vice-versa.

Além destas duas funções, bastante funcionalistas, tratadas por Merton (1957: 78), existem outras que são catalogadas dentro das funções de manutenção, das quais selecionamos três, bastante importantes como que para justificar esta pesquisa que são: as campanhas como meios de difusão dos símbolos políticos; as campanhas como meio de educação cívica, e campanhas servindo para fixar temas de interesse político. Estas três funções, se tratadas conjuntamente na comunicação partido/eleitor, em sua forma publicitaria, que é a que mais se presta para fixar mensagens relacionadas à imagens que se quer transmitir, serviriam para, a partir de alguns elementos notadamente reconhecidos como fontes referenciais do quadro partidário nacional, auxiliar na rápida formação do referencial simbólico.

\section{Objetivos, hipóteses e metodologia}

O objetivo principal desta pesquisa foi, a partir das hipóteses levantadas, buscar pressupostos para a discussão da reformulação das formas de comunicaçao persuasiva que vem sendo utilizadas pelos partidos políticos, com vistas a que possam contribuir positivamente para a formação do referencial simbólico político partidário brasileiro. Este objetivo de pesquisa vem justificado pelo fato de que, apesar do muito (quantitativo) que se faz em termos de comunicação política em suas duas vertentes persuasivas, tanto da propaganda, quanto da publicidade, se tem um resultado muito insignificante (qualitativo), usando-se como paradigma a cultura cívica e de participação do eleitor, no que diz respeito ao reconhecimento dos símbolos nacionais (dentre eles o nome dos partidos, o nome do presidente e de outras autoridades etc.). 
As duas hipóteses principais foram: a) é pela comunicação publicitária que o eleitor toma contato com os referentes simbólicos dos partidos e forma o seu imaginário político e, b) os suportes publicitários gráficos, realizados pelos partidos políticos concorrentes às eleições municipais de 1996, não cumpriram seu papel de comunicação publicitária, com toda a carga informativa e persuasiva que implica mas sim, cooperaram para criar um referencial simbólico confuso na mente do eleitor a que se destinaram. Como hipótese segundária, mas sem deixar de ter importância para o estudo, acreditávamos que, na decisão de voto incide uma serie de variáveis de diferentes procedências, uma das quais é, sem dúvida, a comunicação publicitária, se bem, não seja a única, apesar de ocupar um lugar muito importante.

A metodologia aplicada foi a da entrevista estruturada com perguntas fechadas e algumas abertas, e que faz parte de uma técnica de pesquisa bastante eficaz em alguns casos, onde se necessitam algumas informaçoes objetivas, mas qualitativas e melhor ainda se é aplicado de forma direta e pessoal, como foi realizado neste estudo.

Resumo da metodologia da entrevista aplicada:

1. Tema da entrevista: Cultura Cívica: o referencial simbólico político do eleitor brasileiro

2. Técnica: o estudo foi realizado por meio da técnica de entrevista pessoal, com questionário e cartão de estimulo visual.

3. Âmbito do estudo: municipal, restrito à área urbana do municipio de Porto Alegre, incluindo todo o tipo de população, inclusive aquela residente nos bairros de periferia.

4. Universo: Individuos de ambos os sexos, que estão obrigados pela constituição a exercer o dever do voto, ou seja, com idade compreendida entre os dezoito anos completos e os sessenta e cinco.

5. Estratificaçao da amostra: A estratificação da amostragem foi realizada por bairros e por condiçao socioeconômica cultural: $\mathrm{O}$ critério utilizado para a seleçao dos bairros foi o utilizado pela Prefeitura Municipal de Porto Alegre para a cobrança do IPTU (Imposto sobre propriedade territorial e urbana). 
6. Instrumento de coleta de dados: A pesquisa foi feita por meio de questionário impresso, com perguntas fechadas e algumas abertas. Para algumas perguntas, foram mostrados cartões com estímulos visuais (simbologia gráfica dos partidos).

7. Método de seleção: por rotas aleatórias.

8. Controle: $\mathrm{O}$ controle das entrevistas foi realizado pela professora coordenadora do projeto e constou de verificação pessoal e aleatória da aplicação de $20 \%$ das entrevistas. O método consta de verificar, em datas, horários e residências se a equipe de entrevistadores esteve realmente no local e se aplicou o questionário, por duas maneiras: $20 \%$ por contato pessoal e $80 \%$ por contato telefônico.

9. Data da aplicação das entrevistas: julho de 1997

10. Entrevistadores: Janini Abudes Pedroso (aluna bolsista) e a própria pesquisadora.

11. Coordenação: Prof. Dra. Neusa Demartini Gomes

A análise dos dados foi realizada de vários ângulos diferentes, e forneceu informações sobre o eleitor e que interessavam para complementar o estudo realizado:

- Identificação partidária dos eleitores.

- Conhecimentos que demonstraram ter sobre as diferenças ideológicas partidárias.

- Conhecimentos que demonstraram ter sobre funções dos políticos.

- Interesses que demonstraram ter sobre o controle do trabalho dos políticos eleitos.

- Meios de informação pelos quais foram informados sobre os partidos e candidatos.

- Nível de recordação que demonstraram ter a respeito dos símbolos oficiais dos partidos políticos.

- Nível de aceitação da publicidade eleitoral.

Recordação ordenada dos elementos dos suportes das campanhas publicitárias eleitorais que chamaram mais a atenção dos eleitores. 


\section{Conclusões}

Todos os indícios confirmaram que os receptores de grande parte das mensagens não receberam, por meio da publicidade eleitoral, uma comunicação suficiente e clara, em sua dupla vertente informativa e persuasiva, de maneira a que pudessem eleger seus candidatos com condições de identificarem, pelo menos, a que partido pertenciam. Os códigos cromáticos e textuais colaboraram para que nao ocorresse uma informação correta. A confrontação do eleitor com os suportes gráficos, na totalidade de seus contextos, ou com suas unidades fragmentadas, conduz a concluir que, para os receptores, deixam muito a desejar como comunicação intencional.

Encontramos suportes gráficos e até mesmo spots para televisão e rádio, de candidatos pertencentes a um mesmo partido, que, submetidos à leituras por parte de receptores, fizeram com que estes confundissem os partidos, ou colocassem candidatos em partidos antagônicos, isto porque os referentes simbólicos, como cores e slogans eram iguais, e inclusive, grande parte deles não possuia siquer sigla de partido. Esta omissão (de siglas e nomes de partidos) faz com que haja dificuldades de reconhecimento dos códigos de comunicação partidária, denotando o que já havíamos encontrado em uma outra pesquisa, realizada antes desta, que demonstrou um grande "personalismo" na comunicação eleitoral de candidatos, inclusive muitas campanhas sem nenhum vínculo visual ou programático com o partido político ao qual os candidatos pertenciam.

O eleitor brasileiro nao recebe, por parte de partidos e candidatos, informações claras de modo a que contribuam para o seu desenvolvimento cívico: a maior parte desconhece os nomes dos partidos, suas siglas ou legendas, seus códigos cromáticos, seus slogans e seus logotipos. Estes elementos textuais e icônicos sao importantes para a fixaçao da identidade partidária dos diferentes partidos que formam parte da oferta eleitoral.

Sabemos que, utilizando as palavras de Kientz (1976: 67) "o receptor não é um individuo no qual os mass midia imprimem sem encontrar resistência: ele reage, filtra e confronta suas impressoes com as de outros." Mas, nem todos os receptores brasileiros alcançaram um grau de desenvolvimento cultural que lhes permita cotejar a publicidade eleitoral que recebem pelos diversos meios, e tirar suas próprias conclusoes. A pesquisa demonstrou que os cidadaos que estão 
melhor preparados para exercitar a comparação política e eleitoral são aqueles cultural e economicamente identificados, na pesquisa, como os grupos A e B, ou seja, uma minoria. Mesmo assim, também entre eleitores dessas classes houve respostas confusas.

Ao situar-se no campo intangível das idéias, a linguagem política tem que ser formalmente inovadora ou então, conservadora. Isto vai depender dos objetivos que o emissor quer atingir. No caso de eleições, o conservadorismo no uso dos símbolos traz algumas vantagens, importadas da publicidade comercial e que já foram testadas: a marca dos produtos.

Se bem fixadas na mente do eleitor, estas imagens irão constituir o referencial simbólico do quadro partidário a que estão expostos.

Como comunicadores e antes, como educadores, acreditamos que um eleitor bem informado pode perceber a sucessão de acontecimentos políticos e pode, inclusive, contrastar as suas fontes de informação, comparando a publicidade dos demais partidos e candidatos, criando entao condições para eleger os líderes que mais mereçam sua confiança.

A principal justificativa para esta pesquisa está no fato de que forneceu conhecimentos que serviram ara uma reflexão a cerca do amplo tema da comunicação política e de seus objetivos, os quais raramente são fixados com a preocupação de contribuir para a construção do desenvolvimento do cidadão.

Entendemos que uma pesquisa como esta pode ser aproveitada com objetivos pragmáticos, mas não evidentemente, manipuladores. A intenção foi a de acrescentar alguns conhecimentos que sirvam para esclarecer a informação e criar formas de comunicação publicitária que sejam mais útil do ponto de vista da contribuição para o desevolvimento da cultura cívica do eleitorado, e conforme Roiz (1994), explorando de forma positiva sua potencialidade como meio e mensagem de pura manipulação persuasiva.

Email:ndegomes@music.pucrs.br

\section{Bibliografia}

Almond, G.A. y Verba, S (1970), La cultura cívica. Madrid: Euramérica.

Barreto, V. - Voto e representaçao, curso de introduçao à Ciência Política. Brasilia: Ed. Universidade de Brasilia. 


\section{Neusa Demartini Gomes}

Candido, J.J.(1992), Direito eleitoral brasileiro. Baurú: Edipro.

Cavalcanti, T. y Dubnic,R. (1964), Comportamento eleitoral no Brasil. Fundaçao Rio de Janeiro: Getulio Vargas.

Coneglian, O.(1992), Propaganda eleitoral. Curitiba: Juruá Ed

Cot, J.P. et Gaborit,P (1977), Citoyens et Candidats, la pratique des élections. Collection Defense d'ignorer. Paris: ed. RobertLaffont.

Cotteret, J.P. (1973), La comunicación política. El Ateneo. Buenos Aires.

Cronkhite,G. (1975), La persuasione. Comunicazione e mutamento del comportamento. Milano: Ed. Franco Angeli.

Di Palma,G. (1990), To Craft Democracy: An Essay on Democratic Transition. Berkeley. USA.: UCLA Press. Domenach, J.M.(1993), Propaganda Política. Barcelona: Edicions 62.

Duverger,M. (1970), Instituciones políticas y Derecho constitucional. Barcelona: Ed. Ariel. (1968), Sociologia política. Rio de Janeiro: Ed. Forense.

Ferrer Rodriguez, E. (1992), De la lucha de clases a la lucha de frases - De la propaganda a la publicidad. Madrid: El País S/A Aguilar S.A.

Ferreira, P. (1992) As eleiçoes municipais e o municipio na Constituiçao de 1988. Sao Paulo: Ed. Saraiva. Garcia, N.J.(1982), que é propaganda ideológica. Sao Paul: Ed. Brasiliense.

Gomes, N.D., (1997), "Reflexoes sobre a publicidade eleitoral brasileira: o emissor e sua contribuiçao para a consolidaçao da democracia", in Revista Famecos núm 7. pucrs. Porto Alegre.

González Lopez, L. (1977), Las campañas electorales - Propaganda y política en la sociedad de masas. Madrid: Fundación Juan March. Editorial Ariel.

(1990), "Simbolos y estereotipos en la comunicación política", in Revista Universitaria de Publicidad y Relaciones Publicas $n^{\circ} 1$. Madrid: Facultad de Ciencias de la Información.Universidad Complutense de Madrid.

Grimau,C. (1981), "Cartel político y publicidad comercial”, in Bonet, C. - El arte del franquismo. Cátedra. Madrid.

Greenstein,F.I.(1974), Democracia y partidos políticos en Norteamerica. Barcelona: Ed. Labor. Herreros Arconada,M. (1989), Teoria y Tecnica de la Propaganda Electoral. Barcelona: Ppu.

Instituto Nacional de Publicidad (1988), Análisis y efectos de las campañas de publicidad política. Madrid.

Klaus,G. (1979), El lenguage de los politicos. Barcelona: Editorial Anagrama.

Kraus, S. y Davis, D. (1991), Comunicación masiva: sus efectos en el comportamiento político. México: Ed. Trillas:Sigma.

Krippendorff, K. (1990), Metodologia de Analisis de Contenido. Buenos Aires: Paidós.

Laurens, A.(1980), Le métier politique, ou la conquête du pouvoir. Paris: Alain Moreau..

Lamounier, B. y Cardoso, F (1978), Os partidos e as eleiçoes no Brasil. Rio de Janeiro: Ed. Paze Terra.

y Meneguelo, R (1976), Partidos Políticos no Brasil. Ed.Alfa-Omega. Sao Paulo.

y Souza, A. (1990), "La elaboración de la nueva Constitución: un nuevo examen de la cultura política brasileña", in Revista Documental de Ciencias Sociales Iberoamericana. Madrid: Sociedad Editorial Sintesis.

Maravall, J.M (1982), La política de la transición. Madrid: Ed. Taurus. 


\section{A Publicidade Eleitoral na Construçao do Referencial Simbólico Político Partidário do Eleitor Brasileiro}

Mendelsohn, H.(1973), "Some reasons why information campaigns can succed" in Public Opinion Quartely.

Muñoz Alonso, A. (1989), Política y nueva comunicación. Madrid: Fundesco.

Muñoz Alonso, A. et al, (1990), Opinión Pública y Comunicación Política. Madrid: Eudema Universidad .

Paiva, M.A.P. (1985), Direito Político do sufrágio no Brasil(1822-1982).. Sao Paulo: Brasilia. Ed. Thesaurus

Pertence, S. (1993), "A "desglamourizaçao" da propaganda eleitoral", in Revista da Associaçao Brasileira de Radio e Televisao núm 86. Brasilia: ABERT.

Prezeworski, A. (1992), Democracy markets and libealization East and South. USA: Lasa. University of Chicago.

Roiz, M.C. (1994), Técnicas mdernas de persuasión. Madrid: Eudema Universidad.

Reis, E.P. (1992), Transitions East and South: the theoretical challenge. Rio de Janeiro: luperj.

Touraine,A.(1992), Beyond social movements? Theory, Culture and Society, v.9. 